expect to publish, will justify me in asserting. For the present I shall only say, that interested motives powerfully operate in the healing art, to dissuade us from the publication of errors committed in diagnosis, while the multifarious publication of wonderfully successful cases is discouraging to the hope that any but the marvellous will be acceptable.

Feeling the force of this hypothesis, and unwilling just now to infringe upon it, I shall, perhaps, obtain a reading for my case by the novelty of its selection. I do not offer it as having a claim to originality, although it is the only one of the kind I have seen in a practice of twenty years, that was not the consequence of parturition, or of polypus uteri, but I do offer it as one, exhibiting conspicuously two points; first, the great advantage a practitioner has who is in possession of a knowledge of midwifery, over one, however eminent, who is unacquainted with it; and, secondly, the danger incurred by practitioners wishing to shorten the road to public favour, by endeavouring to be characterised for an off-hand dash in practice, as well as for delicacy and forbearance in the examination of female disease. The following case will exemplify that, by yielding to misplaced modesty, an irreparable mischief is sometimes done to the confiding patient, as well as to the repu. tation of the practitioner, whose quantum of success on such grounds may encourage him by habit, to the dangerous supposition, that he is gifted with a talent of making a safe diagnosis on a view of his subject as superficial, as in the following

Case.-I was called on at midnight, some time ago, to visit Mrs. who said she was subject for years to painful attacks of gravel, and bearing down; that the present attack was the severest, as she had now, in addition, a painful swelling, and was in great agony, as, indeed, her piteous moanings indicated. Having mentioned a bearing down and swelling, I requested to be allowed to examine, on which she conducted my hand under the bedclothes to feel outside her shift; and on my urging to be allowed to examine more properiy, I was informed, that the eminent practitioner whom she had consulted in all former attacks had never been so unreasonable, but from her description had always prescribed something for her. Being, perhaps, less punctilious than those who preceded me in her case, I urged that it was necessary to examine, was permitted, and found a tumour pending from the vulva, and extending between the thighs, very painful to the touch, and of the size of a new-born infant's head. There was a painful desire to make water, and at every effort the tumour received an impetus that seemed to swell and infiame it more. I tried ineffec- tually to pass the catheter, and return the tumour to its proper position within the os externum; but seeing that $I$ had failed in both attempts, I directed fomentations, an emollient injection, and a draught of castor oil with laudanum, in expectation of soothing until my visit in the morning, at whick time I succeeded in introducing the catheter, and giving exit to a quantity of urine; and subsequently returned the whole of the tumour, without any formidable difficulty: it was of an oblong, cylindrical shape, the greatest diameter being next the labia.

The absence of the os tincæe at the lower part, distinguished it from prolapsus; and its hardness, redness, and greater sensibility, together with the want of neck or peduncle, from polypus. I think I need scarcely say, this was a case of inverted uterus, mistaken, extraordinary as it may appear, during its incomplete stage, for gravel. In consequence of which mistake she had been for years dragging on a miserable life, for want of that aid, the necessity of which a more minute investigation would have made apparent. I am happy to say, the complaint, mistaken and treated as a case of gravel, for the space of twelve years, has now, even at her late period of life, been perfectly relieved, simply by the use of a globular pessary.

\section{DISEASE OF THE CACUM AND}

\section{A P P E DIX VERMIFORMIS,}

ISSUING IN A FISTULOUS OPENING THROUGH THE ABDOMINAL PARIETES.

\section{To the Editor of The LANCET.}

SIR:-The following case occurred in a patient admitted into the Manchester Royal Infirmary, whilst I officiated as clerk to Dr. J. L. Bardsley. If you consider it worthy of publication, in connection with the recent investigations on cæcal disease, perhaps you will be kind enough to insert it in yout excellent Periodical. I am, Sir, your obedient servant,

\section{Sajford, Manchester.}

$$
\text { G. Sovtham, M.R.C.S.I. }
$$

June 26, 1840.

May 15, 1835. Thomas Ryley, aged 22 years, weaver, stated that twelve months previous to his admission he received a severe blow on the lower part of the abdomen, to which he attributed his present affiction. It commenced with pain in the abdomen, at first slight, and not incapacitating him from following his employment during the first six months of its existence. From this period it became more violent, and a tumour gradually developed itself on 
the right side, immediately above Poupart's ligament.

When admitted, the abdomen was very tender, and an obscure tumour could be felt on the right side of the linea alba above the groin; it was very firm, and pressure upon it caused pain. His bowels were moved daily, the fæces being generally light coloured and loose; the swelling continued to extend upwards until the 23rd of July, when it burst at the umbilicus, and a considerable quantity of fæculent matter of a light colour and thin consistence was discharged; this gave immediate relief to the pain which had accompanied its formation. Fæces were discharged almost daily from the umbilicus, as well as from the anus, the quantity varying in proportion to the violence of the diarrhoea which was present. He died about the middle of September, and on examination the following appearances were detected:-

The lower portion of the ileum and the cæcum were extensively thickened in consequence of lymph having been thrown out on some previous occasion. A sinus was found extending from the cæcum to the umbilicus; it was formed by the appendix vermiformis cæci, which was bent upwards and adherent to the anterior parietes of the abdomen, to within about an inch of the umbilicus, with which it communicated by a short fistulous canal. The appendix was thickened and dilated, and the shell of a hazel nut was impacted in its middle portion.

\section{CARIES OF THE STERNUM WITH} ULCERATION OF THE LUNG.

Sir:-As the following case may present something of interest to many of your readers, I shall feel obliged by its insertion in your valuable Journal. I am Sir, your obedient servant,

Tiverton, June 22, 1840.

\section{G. Coward.}

ULCERATION OF TIE LUNG, ORIGINATING IN CARIES OE THE STERNUM.

A full, powerful man, but of a decidedly strumous diathesis, was affected with circumscribed inflammation over the sternum, and oppression in the chest, about three months since; symptoms which he attributed to an accidental chill. The local appearances at this time were circumscribed odematous tumefaction; heat, pain, and redness, situated opposite the mamma a little to the right of the mesial line. The patient complained of deep-seated pain and oppression beneath the externally affected part; there was congh, dyspnœa, and slight expectolation. The general symptoms were febrile : quick, hard pulse; hot skin, thirst, white tongue, and constipated bowels. As the morbid process proceeded, the ex istence of pus became evident, and the swelling increased, with fluctuation, whilst the geveral symptoms assumed the hectic type. By the application of poultices the progress of the pus to the surface was facilitated, and after some days the abscess spontaneously broke, discharging ill-conditioned and offensive matter. The sternum was found to be carious : it was rough and excavated, and continued to discharge offensive pus as the morbid process increased. Notwithstanding active and judicious treatment, the disease continued to exlend until the sternum was completely perforated and the lung exposed, which had doubtless contracted extensive adhesions by the opposing surfaces of the pleuræe during the increase of disease. The lung itself now became affected: a large ulcerated cavity was soon formed (most probably in the middle lobe of the right side), and air escaped easily by any respiratory effort. In this condition, with but slight aggravation of symptoms, he still continues, and at present he presents the following morbid signs, local and general. There is an ulcerating cavity at the point indicated, of about two or three inches in extent, through which air readily escapes in any powerful respiratory effort, but not during ordinary breathing; the margin of this cavity is red and tumid, and there is considerable tumefaction over a similar spot on the left side. The patient complains very little of pain, but the inflamed portions are extremely tender. There is occasional cough and expectoration, and the fever present is hectic: there is a permanently quick pulse, exacerbations of fever occurring in remittent paroxysms, occasional night sweats and thirst, whilst the strength fails rapidly; but there is no emaciation, as of late; the countenance has become puffy and odematous, and of a leucophlegmatic aspect; and there is a decided tendency to general anasarcous effusion, as is evinced in the appearance and feel of the general surface.

Judging from the negative effect of treatment, the strumous diathesis, and the steady but decided advance of bad symptoms, the prognosis is unfavourable; whilst, on the contrary, the patient's youth, usual strength, and active habits, are in his favour.

Health of the ARmy.-In the Supple. mentary Estimate of the Office of Ordnance, 1840-1841, laid, on the 1st instant, before the House of Commons, the sum of f27S1 is proposed to be expended in the erection of Ball and Fives Courts in the Barracks of Great Britain, under the au. thority of a Treasury resolution, passed in April last. 